\title{
Frontal Sinus Fractures
}

\author{
Anthony Echo, M.D., ${ }^{1}$ Jared S. Troy, M.S., ${ }^{1}$ and Larry H. Hollier, Jr., M.D. ${ }^{1}$
}

\begin{abstract}
The management of frontal sinus fractures has changed over the past 20 years. Whereas the indications for an invasive procedure had been much broader in the past, it has become more common to treat these fractures conservatively, due to improved imaging modalities, the advent of endoscopic surgical treatment of the nasofrontal outflow tracts, and the improved understanding of frontal sinus physiology. A variety of algorithms have been proposed for the management of frontal sinus fractures; however, we present a simplified treatment algorithm, which uses cranialization, obliteration, reconstruction, observation, and endoscopic sinus surgery.
\end{abstract}

KEYWORDS: Frontal sinus fractures, nasofrontal duct, nasofrontal outflow tract, mucocele

F rontal sinus fractures account for 5 to $15 \%$ of all craniofacial fractures related to trauma. ${ }^{1-3}$ However, over the past 20 years, frontal sinus fractures have undergone a transformation in terms of management. Generally speaking, management has become much more conservative due to the better understanding of frontal sinus fracture management and the advent and expertise developed in endoscopic sinus surgery. ${ }^{4-8}$ Increasingly, many fractures that were previously operated on are now followed radiographically and treated endoscopically only if complications arise. ${ }^{5,9-11}$ It is critical to evaluate these fractures properly and have a firm grasp on how to apply the correct surgical intervention to manage these injuries. Although other algorithms have been proposed for the management of frontal sinus fractures, ${ }^{12,13}$ we present a simplified algorithm based on the available treatment modalities, addressing our cranialization, obliteration, reconstruction, and observation criteria.

\section{EVALUATION}

Most patients presenting with frontal sinus fractures have sustained substantial craniofacial trauma. Motor vehicle accidents were once the most common source of these injuries ${ }^{14-17}$; with the advent of airbags, however, they are much less frequent. ${ }^{18}$ Severe aggravated assaults are much more commonly seen now as the underlying cause, as are motor vehicle-pedestrian accidents. ${ }^{19}$ Because of the significant underlying forces involved, many of these patients will have also sustained intracranial injuries, ${ }^{20}$ requiring a multidisciplinary approach to the patient's overall management.

It has become routine practice for patients presenting with severe facial trauma to undergo a computed tomography (CT) scan of the face, head, and neck. Because of the high-energy mechanisms associated with frontal sinus fractures, it is not uncommon to see concomitant intracranial injuries and cervical spine injuries; therefore, the neurosurgical service is usually involved in the patient's care.

Any CT scan done to evaluate the brain will also adequately evaluate the anterior and posterior tables of the frontal sinus as well as the nasofrontal outflow tract. In looking at the $\mathrm{CT}$ scan, three elements must be critically evaluated: the anterior table, the posterior table, and the nasofrontal outflow tracts. Specifically, when
${ }^{1}$ Division of Plastic Surgery, Baylor College of Medicine, Houston, Texas.

Address for correspondence and reprint requests: Larry H. Hollier, Jr., M.D., 6701 Fannin Street, Suite 610, Houston, TX 77030 (e-mail: larryh@bcm.edu).

Facial Trauma; Guest Editor, Larry H. Hollier, Jr., M.D.
Semin Plast Surg 2010;24:375-382. Copyright (C) 2010 by Thieme Medical Publishers, Inc., 333 Seventh Avenue, New York, NY 10001, USA. Tel: $+1(212) 584-4662$.

DOI: http://dx.doi.org/10.1055/s-0030-1269766.

ISSN 1535-2188. 
assessing the anterior and posterior table, the degree of displacement must be noted. Along these lines, one should also take particular note of any pneumocephalus that is seen, as it is indicative of the severity of the injury and may push the surgeon toward a more immediate operative intervention. The third critical element is the inferomedial component of the fracture, as this frequently involves the outflow tracts of the sinus. Severe fractures in this area are of a greater degree of concern, ${ }^{3,21}$ as the risk for impaired sinus drainage increases.

On physical exam, one should carefully evaluate the overlying soft tissue trauma. Many of these injuries will have severe lacerations overlying the fractures themselves and elsewhere over the face. In the central region of the forehead, the supraorbital and supratrochlear nerves are likely to have been injured, which would manifest as numbness or paresthesias of the forehead. ${ }^{22}$ This must be carefully documented in this initial evaluation to prevent confusion with respect to the outcome of operative management and its complications.

\section{MANAGEMENT}

There are several indications for surgical intervention with frontal sinus trauma. The first, and perhaps the most obvious, is severe displacement of the anterior table. The potential for postoperative contour deformities warrants reduction and stabilization of these fracture fragments.

Posterior table involvement is perhaps more controversial. Occasionally, one will see relatively mild anterior table involvement with more displacement of the posterior table. The question of how much posterior table displacement is acceptable then arises. The concern with displacement is twofold. First, displaced posterior table fragments may cause a cerebrospinal fluid (CSF) leak through a tear in the dura. One may be able to detect this on physical exam by seeing fluid leaking from the nose. This can be sent for a $\beta-2$ transferrin for confirmation, but it should be presumed to be CSF until proven otherwise. Many patients, however, do not have this and instead simply have what they refer to as a postnasal drip. They can often be heard clearing their throats because of the constant fluid leak. If confirmation is needed, a CT myelogram is helpful in localizing the leak.

The other concern regarding posterior table displacement is entrapment of mucosa within the intracranial space. Trapped mucosa here can lead to mucoceles and cause serious complications. Although some previous algorithms have advocated surgical intervention for posterior table involvement greater than one table width, it is increasingly common practice to intervene only for much more severe posterior table injuries.

The third source of concern in these injuries is the status of what sometimes is called the nasofrontal duct.
This is perhaps more appropriately termed the nasal frontal outflow tract, as it is rarely a distinct duct. This area is most frequently in the inferomedial portion of the frontal sinus and allows it to drain into the ethmoid region. Theoretically, the more severe the trauma in this region, the more likely that the sinus will not drain properly, resulting in a mucocele. Severe injury to any of the above three areas (medial portion of the frontal sinus, frontal sinus floor, anterior ethmoid air cells) should prompt the surgeon to consider operative management in the short term.

As was stated above, management has become increasingly nonoperative in many of these cases due to the ability of surgeons to manage complications endoscopically. Should one elect to not operate on the frontal sinus, the patient should be followed with CT scans at various intervals in the postinjury period. The interval of these scans is not set in stone and should be dictated by the severity of the injuries. In many cases, we will not obtain the first follow-up scan until 3 to 6 months after the injury and will schedule subsequent follow-ups depending upon the findings of that first scan. However, should the patient complain of frontal headaches or nasal drainage, this follow-up interval should be shortened. ${ }^{23}$ Patients should also be encouraged to use nasal decongestants as this certainly helps in promoting drainage of the sinus.

Should a patient present with a small CSF leak and a very small fracture with no other operative indications, time can be given to allow this leak to resolve. It has been reported in the literature that anywhere from 53 to $95 \%$ of CSF leaks will resolve spontaneously. ${ }^{24-26}$ If one is going to manage the CSF leak conservatively, one should counsel the patient that maintaining the head in the elevated position is critical. Keeping the head at or below the level of the heart increases the pressure at the site of the dural tear and decreases the chance that this leak will ever spontaneously seal. In recalcitrant cases, one can consider a lumbar drain to further decrease the pressure at the level of the tear. In any case, persistent leaks beyond 1 to 2 weeks should prompt consideration for surgical intervention.

Should one choose surgery for these injuries, beware of attempting to use existing soft tissue lacerations and their exposure. Rarely are overlying lacerations sufficient to allow visualization and access to repair the injuries, despite some authors' beliefs. ${ }^{13,26,27}$ In essentially every case, a coronal incision should be used. How to perform this is beyond the scope of this article; however, zigzag coronal incisions are generally much better concealed within the hairline. As one takes down the coronal flap, this should be done in the subgaleal plane, preserving the periosteum as potential graft or filler material for harvest if necessary. This also allows one to later harvest a galeal flap from the coronal flap should this be thought necessary. 
A
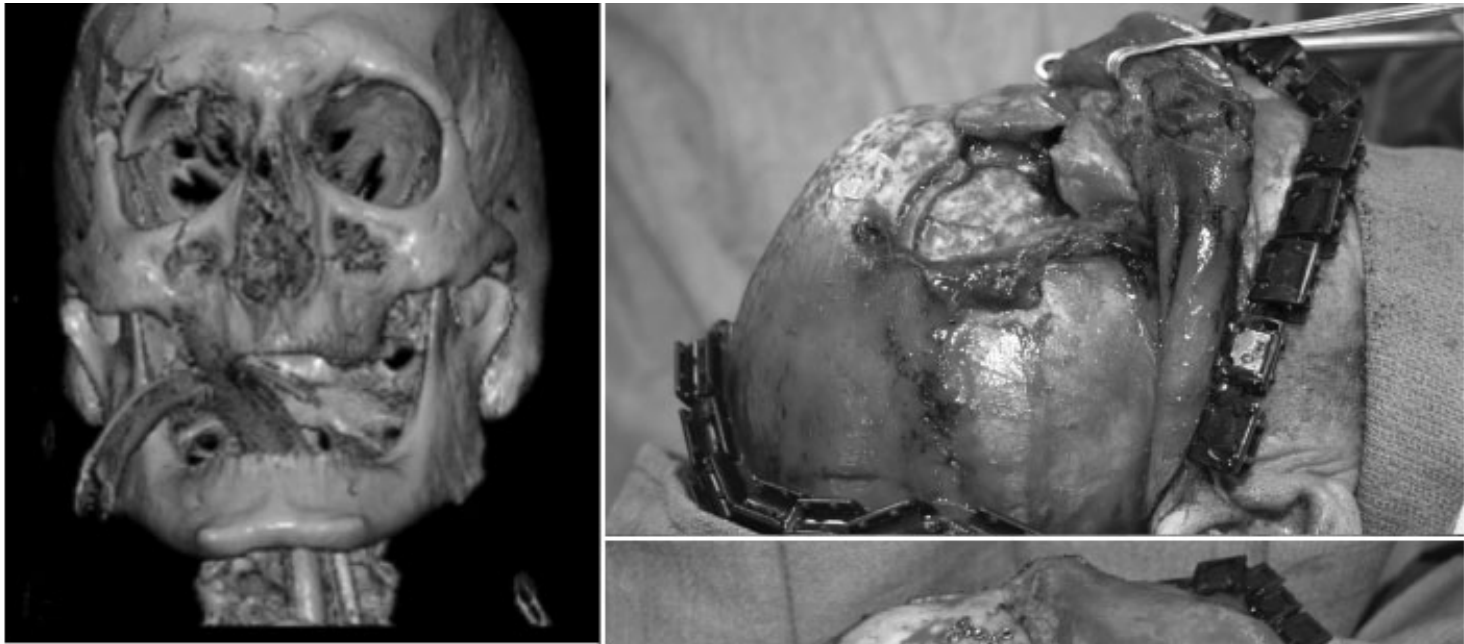

.

B

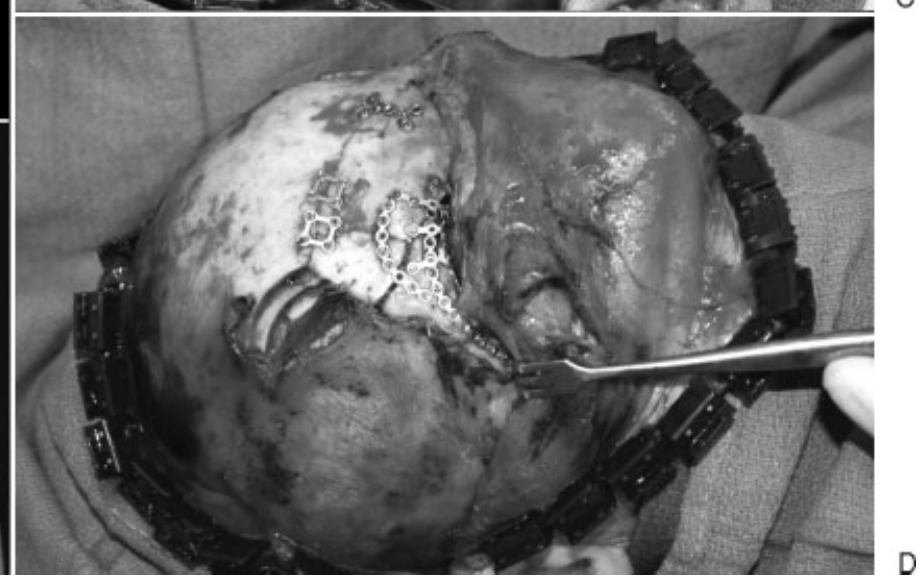

Figure 1 (A) Nondisplaced anterior table fracture with severe displacement of the right lateral supraorbital rim. (B) The frontal sinus is well aerated; therefore, the concern for nasofrontal outflow tract involvement was low. (C, D) The mucosa was left intact, and the anterior table and the supraorbital rim were plated.

Once the level of the fracture is reached, management depends upon the indications for the surgery. For severe isolated anterior table fractures, the fragments need to be reduced and stabilized (Fig. 1). This is sometimes quite difficult as the fragments may be very small. We have found it helpful to make a small template with the fracture fragments on the back table as we remove them. This will aid in replacing them in their anatomic position for subsequent plating. Taking out fracture segments in a piecemeal fashion and simply placing them in a cup makes accurate reconstruction troublesome. When fixating these anterior table fragments, one should consider using a piece of overlying mesh. ${ }^{28}$ If individual plates are used, we have found that postoperative bone resorption can result in small defects of the anterior table and subsequent overlying contour deformities. By placing a mesh on top of the fracture fragments, one can stabilize the bony pieces and prevent soft tissue prolapse, if resorption does occur.

In the event it is believed that the outflow tract is involved, the surgery becomes more complex. In these cases, one needs access to the interior of the frontal sinus for more complete evaluation. This frequently requires removal of the remainder of the anterior table. The safest way to remove this without resorting to a craniotomy is simply to place one prong of a bayonet forceps within the sinus and to mark out the limits of the sinus using the outer prong as a guide. One may also turn down the lights in the room and shine a light source within the sinus and see which portions transluminate. The outer table can then be taken off with an osteotome or saw.

Management at this point depends on the status of the outflow tract. Although many have advocated filling the sinus with dye and determining whether or not it drains to pledgets placed within the nose, this is not a terribly sensitive or specific test. Rather, it is preferable for the surgeon to use clinical judgment as to whether or not the outflow tract is adequately preserved despite the fracture. If it is, the anterior table can simply be plated in its correct position as discussed earlier. If not, the sinus should be obliterated. This involves removing all of the mucosa from within the sinus, plugging the nasofrontal outflow tract, and plating the anterior table.

Sinus mucosa should be removed using either a burr or a $\mathrm{CO}_{2}$ laser. It is very helpful to instill methylene blue dye within the sinus so that the surgeon can determine which areas have been burred and which areas have not. Use of a burr or laser is necessary as there are small invaginations within the mucosa that go within the 
A
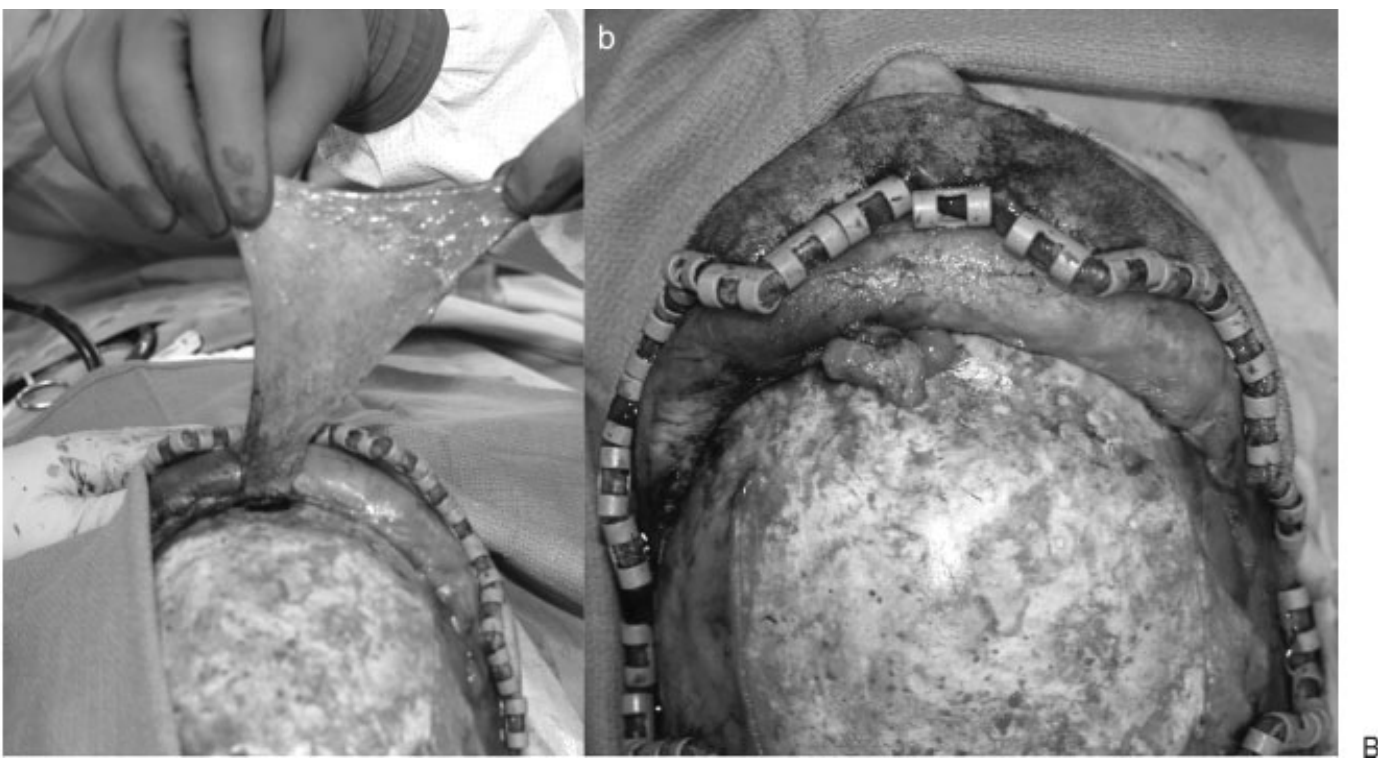

Figure 2 The patient sustained a depressed anterior table fracture involving the nasofrontal outflow tracts. After the removal of the frontal sinus mucosal lining, a pericranial flap was elevated (A) and used to obliterate the frontal sinus (B).

substance of the bone. Simply scraping the mucosa out does not address these anatomic features.

After this, the nasal frontal outflow tract must be obstructed. In many cases, it is quite sufficient just to raise a pericranial flap ${ }^{29-31}$ and seal this down into the outflow tract using fibrin glue (Fig. 2). However, any autogenous substance is acceptable including bone, muscle, or fascia. A greater controversy is the need to fill the remaining empty space of the sinus. There are many advocates for using fat grafts, bone, or other soft tissue to obliterate completely the sinus space itself. Radiographic studies of the fate of this material are variable. Some have shown retention of the material and others have not. However, it is counterintuitive to

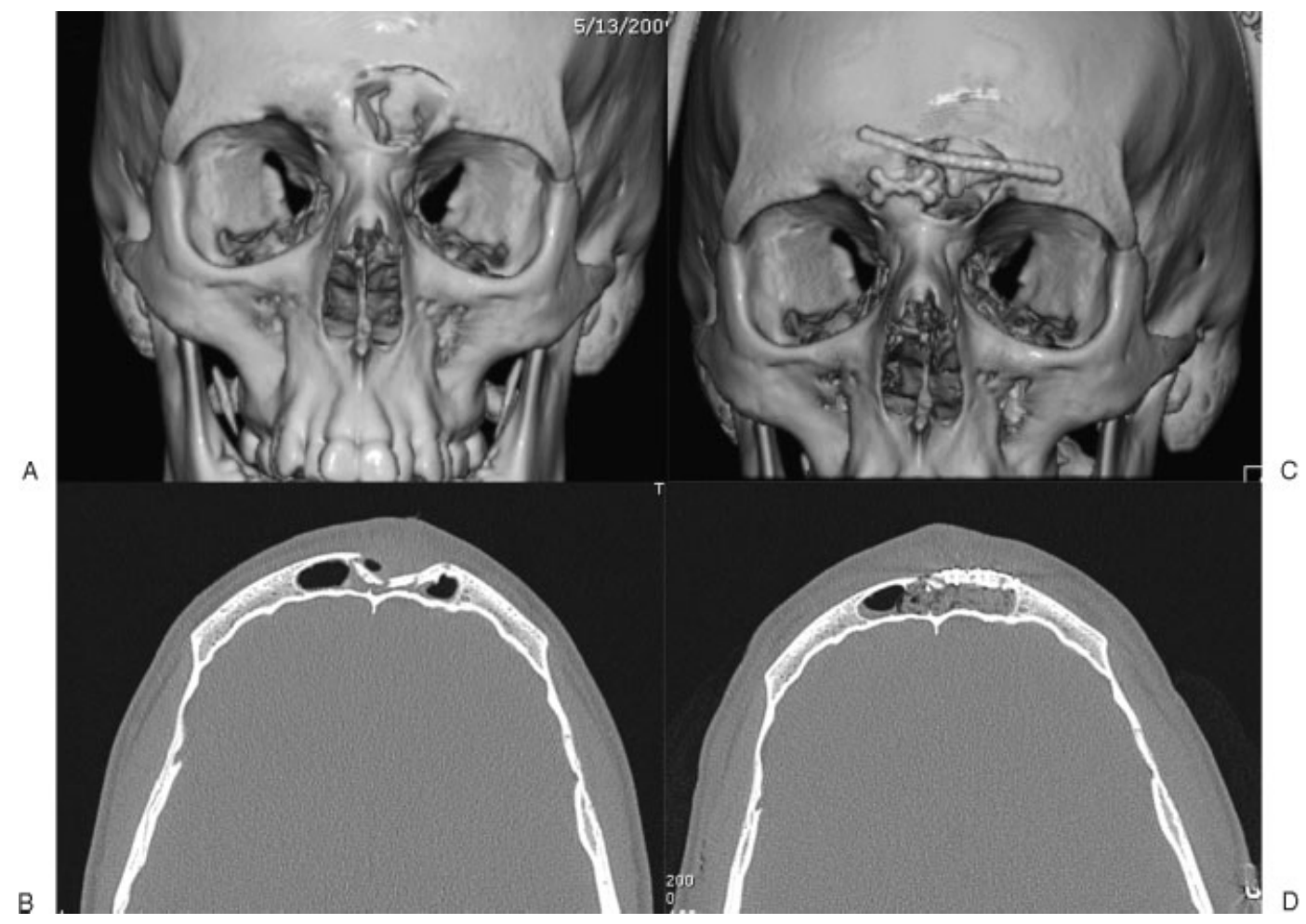

Figure 3 The preoperative $(A, B)$ and postoperative $(C, D)$ images of the patient of Fig. 2, who underwent frontal sinus obliteration with a pericranial flap. The postoperative images demonstrate adequate placement of the pericranial flap and anterior table reconstruction with miniplates. 

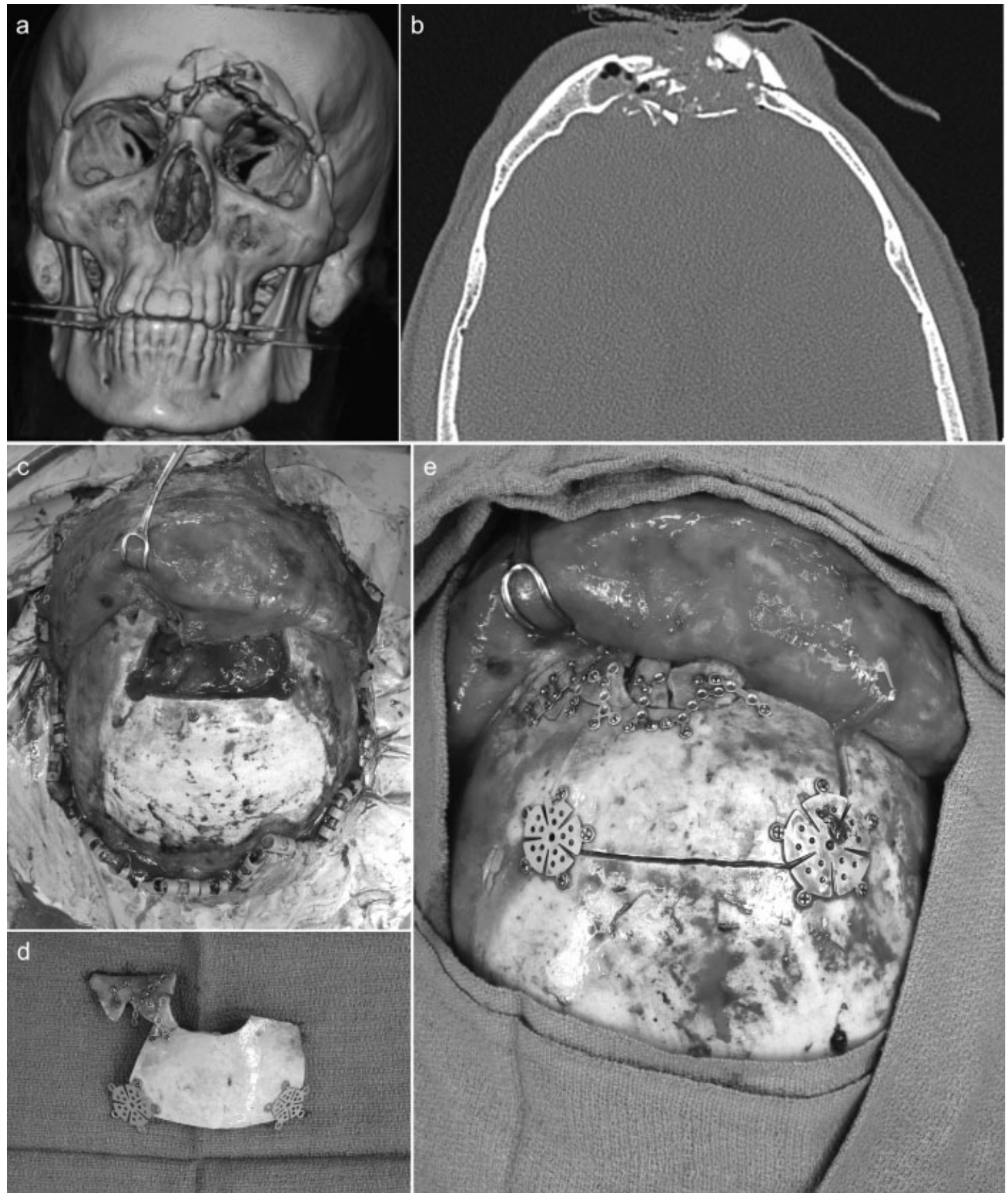

Figure 4 (A, B) A patient with a severely comminuted fracture of the anterior and posterior table of the frontal sinus with involvement of the nasofrontal outflow tracts. (C) A craniotomy was performed removing the remaining anterior and posterior table. A pericranial flap was then placed over the dural repair. (D) The anterior table fragments were assembled on the back table. (E) The reconstructed anterior table was then inset over the pericranial flap.

think that nonvascularized graft material placed in a large cavity will necessarily revascularize and be retained over time. It is our opinion that simply leaving the sinus empty once the outflow tract is plugged is more than sufficient (Fig. 3).

If the posterior table is severely injured, a craniotomy is necessary. Once the forehead fragment including the sinus is removed, it is taken to the back table, and the posterior table is simply taken off. Just as with sinus obliteration, the mucosa on the posterior aspect of the anterior table is also thoroughly removed. At this point, great care must be taken to obliterate the nasofrontal outflow tract. Again, it is acceptable to do so with graft material, such as pericranium and fibrin glue. Some surgeons prefer a well-vascularized flap such as the galeal flap. This certainly provides sufficient tissue to seal the duct. In cases of obliteration, it may even fill the remaining sinus space. The patient should be counseled, 


\section{Frontal Sinus Fracture}

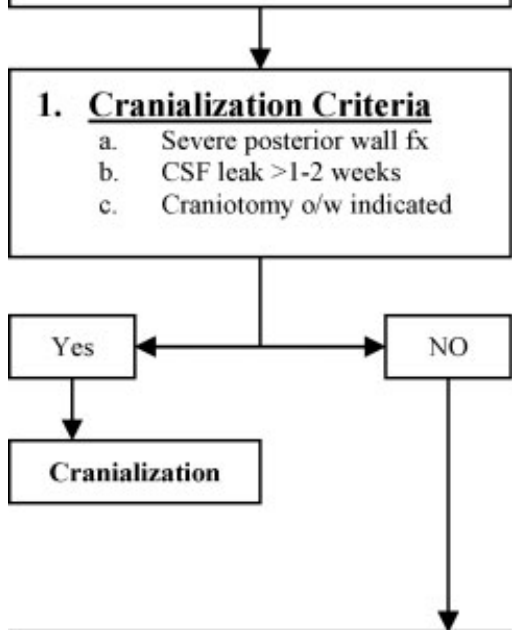

\section{Obliteration Criteria}

a. NFOT obstruction suspected

b. Severe medial sinus $\mathrm{fx}$

c. Severe sinus floor $\mathrm{fx}$

d. Severe ethmoid $\mathrm{fx}$

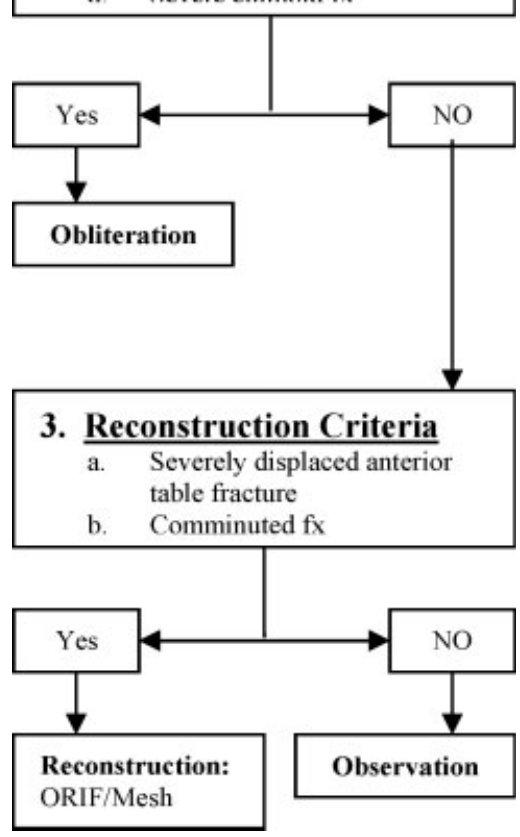

Figure 5 Frontal sinus fracture treatment algorithm.

however, that there will be a contour deformity of the forehead with use of this flap. In the case of cranialization, once the duct is sealed, the forehead should be plated back into position. Once this is done, the brain is simply allowed to expand into the site of the previous frontal sinus, and the craniotomy flap is plated back into position over the pericranial flap or galeal flap (Fig. 4).

\section{TREATMENT ALGORITHM}

A simple treatment algorithm for surgical intervention is illustrated in Fig. 5 and represents a three-step thought process that can be used to effectively manage frontal sinus fractures. ${ }^{3,28}$ As illustrated, the first step in assessing frontal sinus fractures involves assessment of the posterior table of the frontal sinus and determining the need for cranialization. Criteria for cranialization include severe posterior table fracture, CSF leak greater than 1 to 2 weeks, or in any situation where a craniotomy is otherwise indicated. Any patient who meets these criteria would undergo a cranialization of the frontal sinus, obliteration of the nasofrontal outflow tracts, and reconstruction of the anterior table.

In the absence of these indications for cranialization, one next assesses the likelihood of nasal frontal outflow tract obstruction, which is demonstrated by either gross obstruction or the presence of severe inferomedial frontal sinus fractures. Patients meeting the criteria for nasofrontal outflow tract obstruction would then undergo obliteration of the frontal sinus and nasofrontal outflow tracts followed by reconstruction of the anterior table.

Without the presence of cranialization or obliteration criteria, one lastly assesses the need for anterior table reconstruction. The presence of significant contour deformity or comminution signifies the need for reconstruction of the anterior table with plates or mesh placement.

Barring all of these criteria, observation is appropriate as illustrated by other authors. ${ }^{20}$ With observation, patients need close follow-up and serial CT scans looking for signs of subacute or chronic nasofrontal outflow tract obstruction. If noted, endoscopic sinus surgery is a viable initial option in many cases.

\section{COMPLICATIONS}

Complications with frontal sinus fractures tend to be seen late, and most of these center around the development of a mucocele due to retained sinus mucosa. Presentation years after the injury and treatment is the norm. These patients return with complaints of pain or fullness in the region of the supraorbital rim. Scanning will often reveal a sinus filled with mucous (Fig. 6). In some cases, this has eroded through the anterior or posterior tables, making the situation much more serious. Infected mucoceles, or mucopyoceles, are even more serious and may present with sepsis, seizures, or other intracranial manifestations. Management of these depends upon the status of the overlying anterior and posterior tables. If the posterior and anterior tables are intact and the problem is confined to the mucosa, endoscopic drainage of the sinus with enlargement of the outflow tract is an acceptable form of treatment. ${ }^{32}$ However, if the anterior or posterior table has been eroded substantially, consideration must be given to open treatment. ${ }^{33}$ In cases such as this, the anterior table may require autogenous bone grafting to reconstitute its 
A
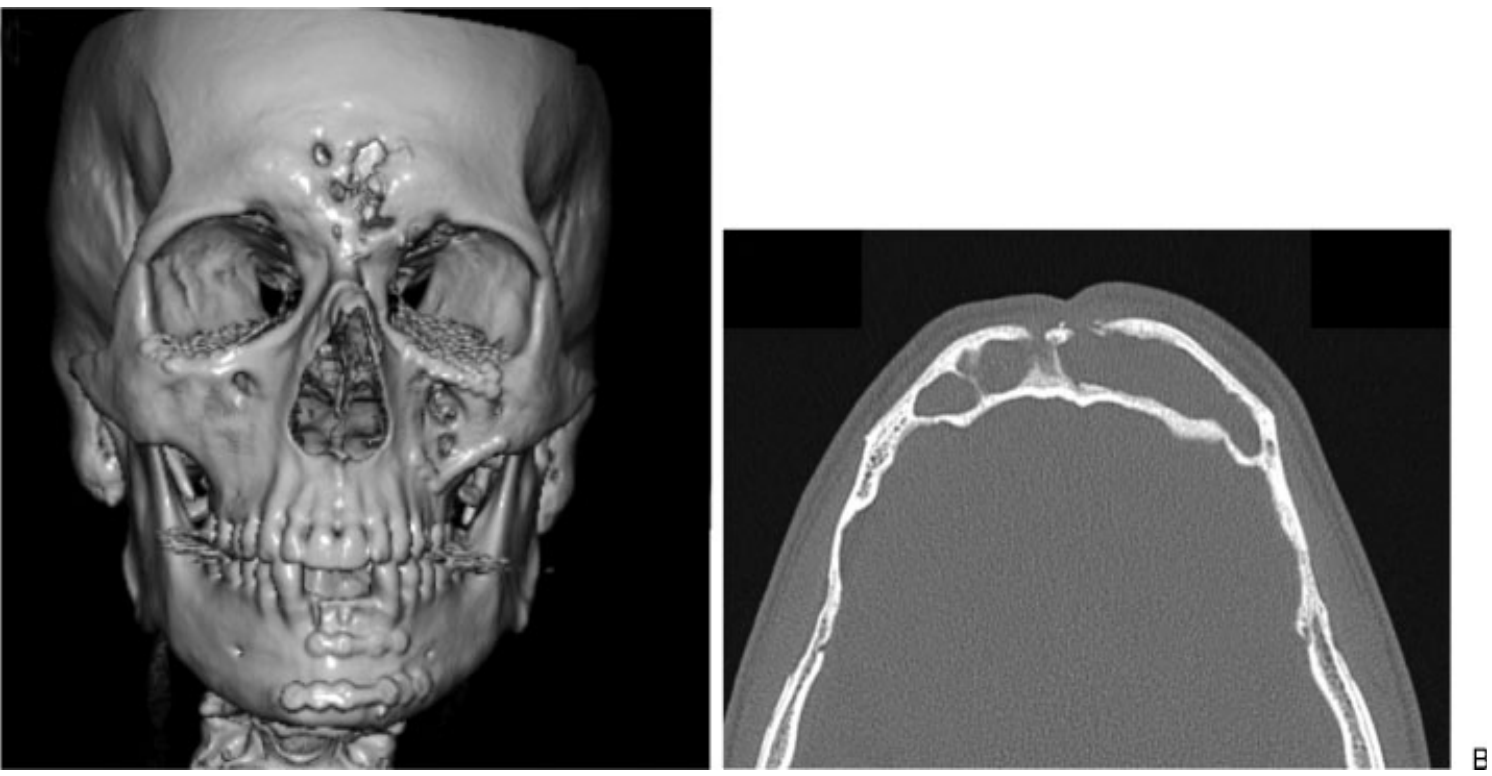

Figure 6 A patient presenting with a mucocele after previous repair and inadequate removal of the frontal sinus mucosa. The anterior table has partially resorbed (A), and the sinus is filled by the mucocele (B).

contour, and for posterior table erosion, craniotomy with galeal flap isolation of the intracranial space.

\section{CONCLUSION}

The management of frontal sinus fractures has transitioned to a more conservative approach over the past few decades due to better imaging modalities, the accessibility of endoscopic sinus surgery, and a better understanding of the frontal sinus treatment options. It is important to have a logical approach to the management of frontal sinus fractures given the number of clinical features that can affect management and the number of treatment options available. To limit the morbidity associated with the invasive nature of these procedures (cranialization, obliteration, reconstruction, observation), our algorithm systematically compartmentalizes the treatment modalities to offer a simplified algorithm for the management of frontal sinus fractures.

\section{REFERENCES}

1. Weber SC, Cohn AM. Fracture of the frontal sinus in children. Arch Otolaryngol 1977;103:241-244

2. Gerbino G, Roccia F, Benech A, Caldarelli C. Analysis of 158 frontal sinus fractures: current surgical management and complications. J Craniomaxillofac Surg 2000;28:133-139

3. Rohrich RJ, Hollier LH. Management of frontal sinus fractures. Changing concepts. Clin Plast Surg 1992;19: 219-232

4. Chen DJ, Chen CT, Chen YR, Feng GM. Endoscopically assisted repair of frontal sinus fracture. J Trauma 2003;55: $378-382$
5. Kanowitz SJ, Batra PS, Citardi MJ. Comprehensive management of failed frontal sinus obliteration. Am J Rhinol 2008;22:263-270

6. Strong EB. Endoscopic repair of anterior table frontal sinus fractures. Facial Plast Surg 2009;25:43-48

7. Strong EB, Buchalter GM, Moulthrop TH. Endoscopic repair of isolated anterior table frontal sinus fractures. Arch Facial Plast Surg 2003;5:514-521

8. Kim KS, Kim ES, Hwang JH, Lee SY. Transcutaneous transfrontal approach through a small peri-eyebrow incision for the reduction of closed anterior table frontal sinus fractures. J Plast Reconstr Aesthet Surg 2010;63:763-768

9. Shumrick KA. Endoscopic management of frontal sinus fractures. Facial Plast Surg Clin North Am 2006;14:31-35

10. Kim KK, Mueller R, Huang F, Strong EB. Endoscopic repair of anterior table: frontal sinus fractures with a Medpor implant. Otolaryngol Head Neck Surg 2007;136:568-572

11. Poetker DM, Smith TL. Endoscopic treatment of the frontal sinus outflow tract in frontal sinus trauma. Oper Tech Otolaryngol Head Neck Surg 2006;17:66-72

12. Bell RB, Dierks EJ, Brar P, Potter JK, Potter BE. A protocol for the management of frontal sinus fractures emphasizing sinus preservation. J Oral Maxillofac Surg 2007;65:825-839

13. Chen KT, Chen CT, Mardini S, Tsay PK, Chen YR. Frontal sinus fractures: a treatment algorithm and assessment of outcomes based on 78 clinical cases. Plast Reconstr Surg 2006;118:457-468

14. Wallis A, Donald PJ. Frontal sinus fractures: a review of 72 cases. Laryngoscope 1988;98(6 Pt 1):593-598

15. Nahum AM. The biomechanics of facial bone fracture. Laryngoscope 1975;85:140-156

16. Gonty AA, Marciani RD, Adornato DC. Management of frontal sinus fractures: a review of 33 cases. J Oral Maxillofac Surg 1999;57:372-379; discussion 380-381

17. Strong EB, Pahlavan N, Saito D. Frontal sinus fractures: a 28-year retrospective review. Otolaryngol Head Neck Surg 2006;135:774-779 
18. Stacey DH, Doyle JF, Gutowski KA. Safety device use affects the incidence patterns of facial trauma in motor vehicle collisions: an analysis of the National Trauma Database from 2000 to 2004. Plast Reconstr Surg 2008;121:2057-2064

19. Erdmann D, Follmar KE, Debruijn M, et al. A retrospective analysis of facial fracture etiologies. Ann Plast Surg 2008;60: 398-403

20. Rodriguez ED, Stanwix MG, Nam AJ, et al. Twenty-sixyear experience treating frontal sinus fractures: a novel algorithm based on anatomical fracture pattern and failure of conventional techniques. Plast Reconstr Surg 2008;122: 1850-1866

21. Rohrich RJ, Hollier L. The role of the nasofrontal duct in frontal sinus fracture management. J Craniomaxillofac Trauma 1996;2:31-40

22. Janis JE, Ghavami A, Lemmon JA, Leedy JE, Guyuron B. The anatomy of the corrugator supercilii muscle: part II. Supraorbital nerve branching patterns. Plast Reconstr Surg 2008;121:233-240

23. Cole P, Kaufman Y, Momoh A, et al. Techniques in frontal sinus fracture repair. Plast Reconstr Surg 2009;123:1578-1579

24. Brodie HA, Thompson TC. Management of complications from 820 temporal bone fractures. Am J Otol 1997;18: 188-197

25. McGuirt WF Jr, Stool SE. Cerebrospinal fluid fistula: the identification and management in pediatric temporal bone fractures. Laryngoscope 1995;105(4 Pt 1):359-364
26. Tedaldi M, Ramieri V, Foresta E, Cascone P, Iannetti G. Experience in the management of frontal sinus fractures. J Craniofac Surg 2010;21:208-210

27. Montovani JC, Nogueira EA, Ferreira FD, Lima Neto AC, Nakajima V. Surgery of frontal sinus fractures: epidemiologic study and evaluation of techniques. Braz J Otorhinolaryngol 2006;72:204-209

28. Lakhani RS, Shibuya TY, Mathog RH, Marks SC, Burgio DL, Yoo GH. Titanium mesh repair of the severely comminuted frontal sinus fracture. Arch Otolaryngol Head Neck Surg 2001;127:665-669

29. Oztürk K, Duran M, Arbağ H, Kele B, Kara M, Uyar Y. [Frontal sinus obliteration with pericranial-subgaleal flap] Kulak Burun Bogaz Ihtis Derg 2010;20:13-17

30. Fattahi T, Dipasquale J. Utility of the pericranial flap in frontal sinus and anterior cranial fossa trauma. Int J Oral Maxillofac Surg 2009;38:1263-1267

31. Donath A, Sindwani R. Frontal sinus cranialization using the pericranial flap: an added layer of protection. Laryngoscope 2006;116:1585-1588

32. Obeso S, Llorente JL, Pablo Rodrigo J, Sánchez R, Mancebo G, Suárez C. [Paranasal sinuses mucoceles. Our experience in 72 patients]. Acta Otorrinolaringol Esp 2009;60: 332-339

33. Soyka MB, Annen A, Holzmann D. Where endoscopy fails: indications and experience with the frontal sinus fat obliteration. Rhinology 2009;47:136-140 